\title{
Appendiceal Carcinoid pT4 TNM Finding v7
}

National Cancer Institute

\section{Source}

National Cancer Institute. Appendiceal Carcinoid pT4 TNM Finding v7. NCI Thesaurus.

Code $C 89930$.

Appendiceal carcinoid with tumor directly invading other adjacent organs or structures, e.g., abdominal wall and skeletal muscle. Penetration of the mesoappendix does not seem to be as important a prognostic factor as the size of the primary tumor and is not separately categorized. (from AJCC 7th Ed.) 